\title{
Research on Teaching Reform and Innovation of the Course of Computer Network Programming
}

\author{
Jinzhu Huang, Meilan Huang \\ Guangxi Technological College of Machinery and Electricity, Nanning, 530007, China
}

Keywords: Teaching reform and innovation, Network programming, Programming design

\begin{abstract}
With the development of computer network, the computer network programming has become an important technology. Computer network programming course has received widespread attention in the colleges of China. However, there are some serious problems in the teaching of computer network programming, such as the backward teaching idea, single teaching model and outdated teaching contents. In view of these problems, this paper puts forward the corresponding countermeasures to provide some references for the relevant researchers.
\end{abstract}

\section{Introduction}

With the rapid development of computer technology and communication network technology, the demand for network talents is very strong, and the field of network communication programming is becoming more and more important. Network programming technology requires students to master the basic theory of computer networks, and use high-level programming language to develop network communication applications. The teaching of network programming needs to pay attention to both the basic and the leading two characteristics. It requires students to master the basic theory and knowledge of network programming, and let them pay attention to the latest development of the network. How to let the students understand and grasp the hot issues of the research and stimulate students' interest and lay a good foundation for the future development in the network application programming work, teaching reform must be considered and important problems to be solved. Network programming technology is a required course in network engineering. The course mainly studies the programming principle and methods under the network environment, through the course of learning network programming, composition and design method of the system concept, programming methods, to enable students to master professional network engineering network programming technology, and can use software tools; through the study of the course, the combination of network and software programming again, to make the students through the network software programming to enhance network theory to understand and grasp, but also can improve the students' network application software programming ability, strengthen students' practical ability to work. Therefore, it is of great practical significance and practical value to study and solve the problem of improving the teaching level of network programming courses in colleges and universities.

\section{Problems of the Course of Computer Network Programming}

Backward Education Ideas. At present, our network programming teaching system is generally used for a brand, and then according to systematic instructions, to guide students to carry out learning, help them understand the content of learning. Teachers pay attention to too much system instruction format, the meaning of parameters in the teaching, ignore the importance of practice, also pay no attention to the machining process, a transfer of knowledge, rote learning will not only lead to deviation of theory and practice, influence the effect of practice, but also will hinder the learning enthusiasm of students, led to the convergence of knowledge points the system is not perfect, the 
instruction into a process of mechanical transmission, the meaning of making the impossible. In view of this phenomenon, in the process of developing numerical control programming teaching in our universities, we must do well the teaching of integration concept so that the theory can be better realized and practical application. The core teaching idea is the key to grasp the key point of teaching and the key point to improve the teaching quality. The teacher will want to teach new programming to students in the lesson teaching of programming, don't let the students memorize something of programming theory, to enable students to understand the significance of the practice. At present, colleges and universities in the teaching of network programming course, teaching ideas is still teaching philosophy in a theoretical model, practical philosophy is not enough, and local cooperation, promote the development of network programming teaching is not doing enough to cultivate students' practical ability. The concept of innovation is not enough, and the performance of College Teachers in the network programming courses teaching content, objectives, teaching methods and so on, not much research, updates and development is not much. The current situation of this teaching concept has seriously affected the effectiveness of network programming teaching in universities, and is not conducive to the healthy development and scientific development of the course.

Single Teaching Models. Teaching patterns and methods appear old-fashioned and simplistic. This is mainly reflected in the practical teaching mode of university teachers with enough, there is no good to carry out the network teaching mode, there will be a good integration of teaching mode and the traditional teaching mode, not well explored a set of teaching mode of school enterprise cooperation from the perspective of network programming, little guide teaching mode of network programming course to change, influence network programming course teaching attraction and the teaching effect to a great extent. The use of discourse in teaching is generally simplistic. This is mainly reflected in network programming course teaching of teachers in Colleges and universities, are generally used for teaching Chinese discourse system, there is no good research network programming course involves a lot of English words, English language carrier of network programming knowledge. It limits the development of the content and mode of network programming course, which is very harmful to the internationalization and information development of network programming course and its teaching. Teachers teach more and students learn less by themselves. Much knowledge is taught, but little ability is cultivated. Network programming teaching content is very rich, we need to put various programming technology throughout the classroom examples and experimental teaching links. Because of the content is much, the hours are few, causes the teaching goal to be unable to achieve frequently. A single classroom teaching, diversification, practical teaching less. The experimental teaching mode of experimental teaching of program design courses followed around the classroom teaching content, the key to verify the contents of the previous classroom teaching, the experimental teaching mode, organic link between the teaching content of network programming and other knowledge effectively and not the students have learned, is not conducive to develop students' programming ability.

Outdated Teaching Content. College Teachers in the deconstruction and reconstruction of network programming curriculum teaching content system, development is not development, a good study of current network technology in network programming, there is no good study of real life and the various sectors of the network programming requirements and expectations. Teachers are not very well studied students what are the special development of network programming, which leads to the network programming course is to keep pace with the times is not enough, seriously affecting the network programming course and its teaching reform and innovation and development. Relying solely on classroom instruction leads to a lack of thorough understanding of the sequence, syntax, and structure of the program, making it harder to spot errors in the program. Programming is a very rigorous and detailed work. Any error in detail can lead to poor machining. If in the process of teaching can be combined with the simulation software or programmer and other equipment, check or graphic simulation of the program, and then analyze the possible errors in the program, can make students better understand and grasp the knowledge, improve the level of programming. Network programming and programming technology, operating systems, data structures, computer networks, network protocol analysis and other closely related courses, and cross each other. Process and thread 
is an important concept in the operating system, the IP address and port is the basic concept of computer network, network protocol and repetitive content programming sections and computer network and network protocol analysis courses have more. Network programming course teaching content covers a wide range, teaching more difficult. If you try to take all the content into a limited period of time, it will make students feel boring and lose their interest in learning. Outdated teaching content has plagued computer network programming students.

\section{Countermeasures of the Course of Computer Network Programming}

Upgrade Teaching Ideas. The traditional teaching idea is to give priority to teaching. Teachers are the main body of the whole teaching process, responsible for the organization, management and evaluation of the whole teaching. Students are only passive receivers in the whole process, and they are the objects of knowledge inculcation. The traditional teaching concept emphasizes knowledge transfer, neglecting the subjective initiative of students. To improve the teaching effect and cultivate students' ability of network programming, we must set up the modern teaching idea which takes students as the main body and takes teachers as the leading part. In the process of teaching, emphasis on students' center and the main body status, stimulate the interest and enthusiasm of students, respect students' personality and skills, cultivating students self-learning ability, to maximize the potential of students; also stressed that play the leading role of teachers, teachers in the teaching process to provide information, ideas and inspiration this method, to supplement knowledge, so as to guide students to question, exploration and innovation. Network programming is a very practical course in the teaching process should be to solve practical problems as a starting point of teaching, strengthen the foundation, strengthening practice, pay attention to the application and guide innovation, make students learn to study, learn to think, learn how to find and solve problems. In explaining the key knowledge points, teachers should bring up cases that are closely related to reality, arouse students' interest in learning, and urge them to think hard. At the same time, the case should be detailed analysis and demonstration of the programming steps, to explain the programming prone to errors, so that students deepen their impression, avoid mistakes in actual operation. Through this kind of teaching method, can improve the students' enthusiasm, and to improve the students' logical thinking ability and practical ability are helpful, but also can reduce the students in experimental class questioning, reduce the pressure of teachers.

Enrich Teaching Models. We advocate improving the current experimental teaching of computer network programming courses, so that students can really understand the importance of network programming experiments, and change the attitude of the experimental class. As a new hot subject, network programming has many kinds of teaching materials, and the content of teaching materials has different emphases. In view of the characteristics of computer network programming course, it is suggested to select the teaching materials which emphasize practical ability. Most of these textbooks focus on programming, and can put forward various kinds of cases for reference. For the subject and requirements of the experiment, teachers should design carefully. The content of programming experiment is the key to arouse students' interest in programming. The teacher should revise the syllabus according to the requirements of the syllabus, and replace the previous verification projects with appropriate design topics and content without changing the requirements of the syllabus. The content of the subject and to reality, let students think study. In the process of writing the program, the teacher is responsible for providing ideas for students to complete the writing process independently. This kind of teaching method can improve students' interest in learning and strengthen their practical operation ability. Arrange students to participate in practical activities. According to the teaching situation, teachers can assess the students' actual ability and arrange them to participate in various social practice activities. As part of a special website of autonomous learning, school or social organization of web design competition, through the experimental exercise outside the classroom, further exercise ability of the students to solve problems and improve the students' operation ability. Computer network programming as a strong practical ability of the subject, in addition to sufficient time for computer operation and programming exercises, the summary of each operation is also very 
important. Teachers should let students summarize the operation experience and record after the computer operation and experiment teaching.

Reform Teaching Content. Teachers should combine the understanding of basic concepts with the training of practical skills in the form of case analysis. Most of the theoretical foundations of network programming have been studied in computer networks and network protocol analysis. Because the above courses emphasize the introduction of theoretical knowledge, the network programming course should first help students' complete theoretical knowledge to practical skills. The case teaching method is adopted in the classroom teaching, and each learning a programming technique should be introduced in the form of actual cases. For example, in the teaching of object oriented programming technology, the first demonstration of the students is familiar with the snake game, then introduce the concept of object, class, inheritance and polymorphism, and guide students to analyze the relationship between class and class which in the snake game. Melt the latest research results into the teaching content. At present, computer network technology is developing rapidly. In teaching, the latest scientific research achievements and key problems that need to be solved are melted into the theoretical teaching content. For example, when teaching network application programming technology, it introduces the development of P2P technology and its applications in the fields of file exchange, scientific computing and video on demand. Following the pace of discipline development, introducing new technologies and cutting-edge problems in theoretical teaching can effectively enhance students' interest in the course. During experiment teaching, repetitive experiments, simulated experiments and analytical experiments were set up. Experimental teaching plays an important role in the whole network programming course. The theory of teaching experiment teaching and network programming course in the same semester, repeated experiment, and arrange some theoretical teaching content reasonable synchronization simulation experiments and analysis of the experiment, cultivate students' independent ability and analysis ability.

\section{Conclusion}

The network programming course teaching reform makes the course teaching idea advanced, teaching method diverse and teaching content modern. It will be a systematic and practical course for the student. In view of the teaching effect, the enthusiasm and initiative of the students are improved, and the students' understanding of network programming technology is deepened. Teaching is an endless process of exploration. In the future, we need to constantly sum up the teaching experiences and continue to carry out teaching reform to improve teaching effectiveness.

\section{References}

[1] Zhang Xiaoming, Du Tiancang, Qin Caiyun. Reform and practice of computer network programming teaching [J]. Experimental Technology and Management, 2010, 27(2): 4-7.

[2] Xiao Zhihong. Task-driven Teaching Method in Network Programming Course Teaching [J].The Guide of Science \& Education, 2015(11): 117-118.

[3] Li Xia, He Xiaoling. Mixed Learning Mode Of Visual Basic Programming Course Based on Network Teaching Platform [J]. Agriculture Network Information, 2016(12): 102-103.

[4] Tang Jing. The Existence of Network Programming Course in Higher Vocational Colleges Teaching Problems and Countermeasures [J]. Information Security and Technology, 2014(12): 84-85+91. 